\title{
The emergence of item-specific encoding effects in between-subjects designs: Perceptual interference and multiple recall tests
}

\author{
NEIL W. MULLIGAN \\ Southern Methodist University, Dallas, Texas
}

\begin{abstract}
The perceptual-interference effect occurs when interference with word perception (by backward masking) enhances later memory for the word. In terms of the item-specific-relational framework (Hunt \& McDaniel, 1993), this effect is similar to other manipulations that enhance item-specific encoding (such as the generation effect). One similarity is that item-specificeffects typically do not arise in betweensubjects designs. However, the present experiment demonstrates that a between-subjects perceptualinterference effect emerges over multiple recall tests. Furthermore, perceptual interference produces both more intertest gains (indexing enhanced item-specific processing) and more intertest losses (indexing disrupted relational encoding) compared with the intact (control) condition. Finally, delaying the mask to a point at which it no longer interferes with perception (266 msec) eliminates both the perceptual-interference recall advantage and the increase in intertest gains. This condition still produces more intertest losses, however. Together, these results imply that a delayed mask disrupts relational encoding but produces no item-specific enhancement, dissociating the two effects of the perceptualinterference manipulation.
\end{abstract}

If a study word is presented briefly and followed by a backward mask, later memory for the word can be enhanced (Hirshman \& Mulligan, 1991; Nairne, 1988). This phenomenon, referred to as the perceptual-interference effect, is typically investigated by presenting words under one of two encoding conditions. In the perceptual-interference condition, words are briefly presented (e.g., for $100 \mathrm{msec}$ ) on a computer screen and then backward masked (e.g., with a row of Xs). In the intact condition, words are presented unmasked and for a longer duration (e.g., $2.5 \mathrm{sec}$ ). In both conditions, the subject's task is to read the study word aloud. Surprisingly, the perceptual-interference condition leads to better memory on several explicit memory tests, such as free recall, cued recall, and recognition(Mulligan, 1999).

This effect is not only counterintuitive, it is contrary to traditional views of memory encoding (see Mulligan, 1999, for discussion). First, traditional theories of memory posit a limited-capacity encoding mechanism (e.g., Atkinson \& Shiffrin, 1968; Raaijmakers \& Shiffrin, 1981; Sperling, 1986). According to this conception, processing the mask in the perceptual-interference condition should require some of this limited-capacity resource, drawing encoding resources from the target item and thus leading to inferior (rather than superior) memory for the perceptual-interference

This research was partially supported by Grant 1-R03-MH61324-01 from NIMH. Correspondence should be addressed to N. Mulligan, Department of Psychology, Southern Methodist University, Dallas, TX 75275-0442 (e-mail: mulligan@ mail.smu.edu). items. Second, the perceptual-interference effect contradicts the traditional view that memory performance improves with increasing presentation duration (e.g., Roberts, 1972). The perceptual-interference words are presented for a fraction of the duration of the intact words, but nevertheless lead to superior explicit memory. Third, this effect is contrary to the principle of transfer-appropriate processing (Morris, Bransford, \& Franks, 1977), which predicts that recognition memory improves with the similarity of study and test conditions (Westerman \& Greene, 1997). The perceptual-interference effect is quite the opposite: In a recognition test, all of the test items are presented intact, yet the perceptual-interference study condition produces better performance than the intact study condition.

However, perceptual interference does not always enhance memory. Mulligan (1996, 1999), drawing on the distinction between item-specific and relational information (Hunt \& McDaniel, 1993), suggested that perceptual interference enhances item-specific processing, rendering better item memory, but disrupts relational and order encoding. A number of results support this view. First, Mulligan (1999) contrasted the encoding manipulations of perceptual interference and list organization, showing that although both manipulations enhanced item recall, they had opposite effects on category clustering during recall (a standard measure of relational processing). List organization increased clustering, whereas perceptual interference decreased it. Second, perceptual interference reduced order memory on the order reconstruction test (Mulligan, 1999, 2000a). Third, when order information is an important determinant of free recall (e.g., short study list of unrelated 
words, brief retention interval), the perceptual-interference effect is eliminated or reversed (Mulligan, 1999). Fourth, Mulligan (2000b) examined the effects of perceptual interference on multiple recall tests, a paradigm used to examine hypermnesia (e.g., Payne, 1987). Prior research has indicated that enhanced item-specific encoding increases the number of item gains across tests, whereas enhanced relational encoding protects against item losses (Burns, 1993; Klein, Loftus, Kihlstrom, \& Aseron, 1989; McDaniel, Moore, \& Whiteman, 1998). Across multiple recall tests, perceptual-interference produced both more item gains and losses, indicating enhanced item-specific encoding coupled with reduced relational encoding. Finally, it has been argued that item-specific encoding affects performance on the explicit test of category-cued recall but has little effect on the implicit test of category-exemplar production (Mulligan, 1996; Mulligan, Guyer, \& Beland, 1999). Perceptual interference affects the former but not the latter test (Mulligan, 1996), and this is consistent with the notion that the perceptual-interference effect is mediated by item-specific information.

This set of findings supports the view that perceptual interference enhances item-specific encoding and disrupts (or at least does not enhance) relational encoding. The itemspecific account of the perceptual-interference effect embeds this effect in a theoretical framework of some breadth (Hunt \& McDaniel, 1993; McDaniel et al., 1998) and relates the effect to others attributed to enhanced item-specific encoding, such as the generation effect, the bizarre-imagery effect, the effects of orthographic distinctiveness, and the enactment effect (Engelkamp \& Dehn, 2000; Hunt \& Elliot, 1980; McDaniel \& Einstein, 1986). The similarities between the perceptual-interference and generation effects are especially intriguing (Mulligan, 2000a; Westerman \& Greene, 1997). The generation effect is what occurs when the generation of words from a word fragment or semantic associate enhances item memory on tests such as recognition and free and cued recall (Greene, 1992).

It should first be noted that there are important differences between the effects of generation and perceptual interference (as there are among all the manipulations encompassed by the item-specific-relational framework), especially regarding implicit memory. For example, generation typically reduces priming on tests of perceptual implicit memory (Roediger \& McDermott, 1993), whereas perceptual interference either produces no effect (Hirshman \& Mulligan, 1991) or increases perceptual priming (Hirshman, Trembath, \& Mulligan, 1994). In addition, generation typically enhances priming on conceptual implicit tests, whereas perceptual interference does not (Mulligan, 1996). However, in the domain of the item-specificrelational framework, there are a number of similarities. For instance, both generation and perceptual interference disrupt order memory (e.g., Burns, 1996; Nairne, Reigler, \& Serra, 1991; cf. Greene, Thapar, \& Westerman, 1998). In addition, when order information is an important determinant of recall, both the generation and perceptual- interference effects can reverse, with the intact condition leading to better recall (Mulligan, 1999; Nairne et al., 1991). In explicit memory, both the generation and perceptualinterference effects are sensitive to the type of stimulus materials, occurring with words but typically not with nonwords (Westerman \& Greene, 1997). Finally, generation and perceptual interference produce similar patterns of item gains and losses across multiple recall tests (Mulligan 2000b, 2001).

A final similarity, one that is central to the present study, is that both effects depend on the experimental design. Specifically, both manipulations produce strong effects on recall in within-subjects (or mixed-list) designs but typically not in between-subjects (or pure-list) designs (e.g., Hirshman \& Bjork, 1988; Mulligan, 1999; Slamecka \& Katsaiti, 1987; Westerman \& Greene, 1997). ${ }^{1}$ Indeed, some between-subjects manipulations of generation produce a reversed, or negative, generation effect in which the intact condition produces superior recall (Steffens \& Erdfelder, 1998). Similarly, other purported item-specific effects, such as orthographic distinctiveness, bizarre-imagery, and enactment effects, are more likely to be found in withinsubjects than in between-subjects designs (e.g., Engelkamp \& Dehn, 2000; Hunt \& Elliot, 1980; Hunt \& McDaniel, 1993, McDaniel \& Einstein, 1986).

Such findings have played a critical role in theoretical accounts of item-specific encoding effects (e.g., Hirshman \& Bjork, 1988; Hunt \& McDaniel, 1993; McDaniel, DeLosh, \& Merritt, 2000; McDaniel, Wadill, \& Einstein, 1988; Mulligan, 1999; Nairne et al., 1991; Slamecka \& Katsaiti, 1987; Steffens \& Erdfelder, 1998). The account based on the item-specific-relational framework (e.g., Hirshman \& Bjork, 1988; Hunt \& McDaniel, 1993; McDaniel et al., 1988; Steffens \& Erdfelder, 1998) suggests that a family of memory effects (e.g., generation effects, bizarreimagery effects, the perceptual interference effect, enactment effects, othographic distinctiveness)can be understood in terms of a tradeoff in the encoding of item-specific and relational information. These encoding manipulations contrast an unusual encoding condition (e.g., the generate condition, the bizarre-imagery condition, the perceptualinterference condition) with a condition that is not as unusual (e.g., the read condition, the common-imagery condition, the intact condition). According to the item-specificrelational account, the more unusual encoding condition attracts greater processing of item features, drawing encoding resources away from the processing of relations between items, thus enhancing item-specific encoding and disrupting relational encoding.

According to this view, free recall relies on both types of encoding. When the encoding conditions are manipulated between subjects, the more unusual condition disrupts relational processing over the entire list and detracts from its typical advantage in recall, causing the itemspecific effect to disappear or even to reverse in free recall for between-subjects designs (e.g., Hirshman \& Bjork, 1988; Slamecka \& Katsaiti, 1987; Steffens \& Erdfelder, 
1998). When encoding conditions are intermixed, the disruption of relational processing produced by the more unusual condition affects both types of items. Consequently, this account proposes equivalent relational encoding for items in a mixed list, which in turn permits the superior item-specific encoding in the more unusual condition to produce a recall advantage (Hunt \& McDaniel, 1993). A more specific version of this account (the order-encoding hypothesis) proposes that the encoding tradeoff is between item-specific and order information, the latter of which is typically conceived of as a specific type of relational information (DeLosh \& McDaniel, 1996; Engelkamp \& Dehn, 2000; McDaniel et al., 2000; Nairne et al., 1991; also, Jurica \& Shimamura, 1999, propose a similar tradeoff in the processing of item and source information).

A second account is the selective rehearsal hypothesis (Slamecka \& Katsaiti, 1987), which proposes that, in mixed lists, subjects rehearse the unusual encoding condition more than the more common condition, effectively stealing rehearsal time from common items. According to this account, when all list items are in either the unusual or the common condition (as in a between-subjects design), the opportunity for differential rehearsal does not arise and consequently the encoding effect is not expected. A related account was developed for the generation effect by Begg (e.g., Begg, Vinski, Frankovich, \& Holgate, 1991) and was applied to the perceptual-interference effect by Westerman and Greene (1997). Like the selective rehearsal hypothesis, this account proposes that different experimental designs induce different encoding strategies. According to this view, when generate and read (or perceptual-interference and intact) items are intermixed, subjects adopt a goal of stimulus identification, a strategy that favors the generate (or perceptual-interference) items because more information about these items must be processed and analyzed in the service of identification. If identification is the goal of encoding, a cursory processing of read (or intact) items suffices, producing less impact on later recall. When read (or intact) items are presented in a separate list, the generate (or perceptualinterference) items no longer serve to induce the minimal encoding goal of identification. Especially under intentional learning instructions, the read (or intact) items are likely to be encoded in a more thorough manner, increasing recall performance to the level of the generate (or perceptual-interference) group. Thus, like the selective rehearsal view, this account proposes that in betweensubjects designs, encoding differences vis à vis recall are minimized. This hypothesisis referred to as the task-demand account (Steffens \& Erdfelder, 1998).

In light of the similarities between the effects of generation and perceptual interference, and the theoretical importance of these effects' dependence on experimental design, the recent results of Mulligan (2001) are important. Mulligan examined the relationship between generation and hypermnesia by examining recall of generated and intact items over five recall tests. Using a between-subjects design and unrelated study words, he found no generation effect on the first (or second) recall test, a result consistent with prior research. However, a robust (and significant) generation effect emerged on later recall tests. This indicates both that the generation effect can emerge in a betweensubjects design and that the experimental design is less of a limiting condition on the generation effect than has been previously supposed (Mulligan, 2001).

The primary goal of the present study was to determine whether this result would generalize to the perceptualinterference effect, anothereffect mediated by item-specific encoding. The perceptual-interference manipulation was implemented in a between-subjects design, and memory was tested with five consecutive recall tests. Given the theoretical importance of the between-subjects null effects for generation and other item-specific manipulations (Hunt \& McDaniel, 1993), it was important to determine whether the results of Mulligan (2001) would generalize to other item-specific effects or whether they would be unique to generation. This research also provided additional data on the similarity of the perceptual-interferenceand generation effects (Westerman \& Greene, 1997; Mulligan, 2000a), and this can help one determine whether between-subjects designs are a true limiting condition of the perceptualinterference effect, as suggested by earlier research (Mulligan, 1999).

There were two subsidiary goals in the present study as well. The first was to use item gains and losses across tests to measure item-specific and relational encoding. Klein et al. (1989; see also Burns, 1993; McDaniel et al., 1998; Mulligan, 2001) demonstrated that conditions fostering item-specific encoding increase the probability of item gains, whereas conditions fostering relational encoding protect against item losses. In a within-subjects design, Mulligan (2000b) found that perceptual interference produced both more item gains and losses across multiple recall tests, indicating enhanced item-specific encoding coupled with reduced relational encoding. Research using alternative measures (Mulligan, 1999) suggests that the same patterns of gains and losses should be obtained in a between-subjects design.

Second, Mulligan (2000a) found that disrupted relational encoding can be dissociated from enhanced itemspecific encoding in the perceptual-interference manipulation. To appreciate this dissociation, one must first note that the perceptual-interference effect arises during perception. If the mask onset is delayed to a point at which the mask no longer disrupts word identification(e.g., $266 \mathrm{msec}$ ), the perceptual-interference advantage no longer arises in recognition (Mulligan, 2000a) or in recall (Hirshman et al., 1994). This implies that the enhancement in itemspecific encoding occurs during but not after initial perceptual processing of the study item (Hirshman et al., 1994; Mulligan, 2000a). Mulligan (2000a) presented study words in three conditions, an early mask condition (100-msec mask onset ), a delayed mask condition (266msec mask onset), and the intact condition. Compared with 
the intact condition, only the 100-msec mask onset condition produced an item-recognition advantage. However, both masking conditions disrupted order memory as measured by the order-reconstruction test. This implies that the enhanced item-specific encoding, found only in the 100 -msec mask condition, can be dissociated from disrupted order encoding, found in both masking conditions. This raises the possibility that a delayed mask, although not facilitating item encoding, would disrupt relational encoding. Mulligan (2000b) speculated that this may happen because the mask acts as an interitem distractor, disrupting the formation of interitem associations (e.g., Li \& Lewandowsky, 1993). In terms of the multiple recall test paradigm, the prediction is that, relative to the intact condition, a delayed mask would produce an increase in item losses across tests (indexing disrupted relational encoding) without the concomitant increase in item gains.

In the present study, these issues were examined by using three encoding conditions implemented in a betweensubjects design: the 100-msec mask onset condition (the standard perceptual-interference condition), the 266-msec mask onset condition (a delayed masking condition), and the intact condition. Memory was tested with a series of five recall tests.

\section{METHOD}

Subjects. Seventy-five undergraduates at Southern Methodist University participated in exchange for credit in psychology courses.

Design and Materials. The encoding condition (intact, 100msec mask, or 266-msec mask) was manipulated between subjects, and the recall test (1-5) was manipulated within subjects. The study list consisted of 44 high-frequency target words (frequency $>70$ according to Kučera \& Francis, 1967) of four or five letters in length. Four additional words, similar in length and frequency, were used as primacy (two) and recency (two) buffers.

Procedure. The subjects were tested individually. Prior to the study task, the subjects were told that they would be presented with a series of words on a computer screen to read aloud. They were instructed to try to remember the words for a later (unspecified) memory test. The subjects in the 100- and 266-msec mask conditions were also informed that the words would be presented very briefly and then covered with Xs. Each trial began with the "get ready" prompt centered on the computer screen and displayed for $0.5 \mathrm{sec}$. Following the prompt, the study word was displayed in the same position as the plus sign. In the $100-$ msec mask condition, the study word was presented for $100 \mathrm{msec}$, and then a row of Xs was displayed in the same position for 2,400 msec. In the 266-msec mask condition, the study word was presented for $266 \mathrm{msec}$, and then a row of Xs was displayed in the same position for 2,234 msec. In the intact condition, the study word was presented continuously for $2.5 \mathrm{sec}$. An experimenter recorded the subjects' responses to the words but provided no feedback.

After the distractor task, the subjects were given the first free recall memory test. The subjects were presented with a blank test sheet and were asked to write down as many words as they could recall from the study list. The test lasted $5 \mathrm{~min}$. The subjects were encouraged to use the entire time to remember as many words as possible. At the end of the first test, the test sheets were collected, and the subjects were then presented with a second free recall test. The subjects were given a new test sheet and again were asked to recall as many words from the study list as possible. The subjects were en- couraged to continue trying to remember words for the entire 5-min test period. This procedure was then repeated for Tests 3-5.

\section{RESULTS}

The alpha level was .05 for all statistical tests. During the encoding condition, the subjects in the 100-msec mask, 266-msec mask, and intact tests identified 98\%, 100\%, and $100 \%$, respectively, of the study words. Although study identification was quite high in all groups, subsequent analyses were performed on the test data, both conditionalized on correct study identification and unconditionalized. The two sets of analyses led to the same conclusions; only the unconditionalized analyses are reported.

Net recall (the number of studied words recalled on a given test; see Table 1) was submitted to a 3 (encoding condition) $\times 5$ (recall test) analysis of variance (ANOVA). All three effects were significant [encoding condition, $F(2,72)=4.07, M S_{\mathrm{e}}=89.06$; test, $F(4,288)=5.74, M S_{\mathrm{e}}=$ 2.32; and the encoding condition $\times$ test interaction, $\left.F(8,288)=9.49, M S_{\mathrm{e}}=2.32\right]$. The significant interaction was investigated first by examining the simple effect of encoding condition within each test and second by examining the simple effect of test within each encoding condition. The first set of analyses revealed no effect of encoding condition in Tests 1 and $2(F=0.82$ and 1.84 , respectively, $p \mathrm{~s}>.15)$. However, a significant effect of encoding condition emerged on Tests 3,4 , and $5[F(2,72)=$ $4.19, M S_{\mathrm{e}}=20.15 ; F(2,72)=8.54, M S_{\mathrm{e}}=18.39 ;$ and $F(2,72)=9.10, M S_{\mathrm{e}}=19.55$, respectively]. Post hoc comparisons (using Fisher's LSD test) showed that the 100msec mask condition produced significantly higher recall than did the 266-msec mask condition on Test 3 , and significantly higher recall than in either the 266-msec mask or the intact conditions on Tests 4 and 5. These results replicate prior research in two ways. First, a delayed mask eliminated the perceptual interference effect (i.e., there were no significant differences between the 266-msec mask and intact conditions; Hirshman et al., 1994). Second, on an initial recall test, a between-subjects manipulation of perceptual interference (i.e., the $100 \mathrm{msec}$ maskintact comparison) produced no effect (Mulligan, 1999).

Table 1

Mean Net Recall and Cumulative Recall as a Function of Recall Test and Encoding Condition

\begin{tabular}{lccccr}
\hline \multicolumn{5}{c}{ Recall Test and Encoding Condition } \\
\cline { 2 - 6 } Encoding Condition & 1 & 2 & 3 & 4 & 5 \\
\hline Net recall & & & & & \\
100-msec mask & 13.2 & 13.2 & 14.1 & 15.4 & 15.8 \\
266-msec mask & 12.3 & 11.0 & 10.1 & 10.6 & 10.6 \\
Intact & 13.6 & 12.8 & 12.8 & 12.3 & 12.8 \\
Cumulative recall & & & & & \\
100-msec mask & 13.2 & 15.8 & 17.6 & 19.4 & 19.8 \\
266-msec mask & 12.3 & 13.6 & 14.1 & 15.0 & 15.8 \\
Intact & 13.6 & 14.5 & 15.4 & 16.3 & 16.7 \\
\hline
\end{tabular}

Note-Net recall and cumulative recall are equivalent on Test 1. 
Table 2

Mean Item Gains, Item Losses, and Pair Frequency Scores as a Function of Recall Test and Encoding Condition

\begin{tabular}{lccccc}
\hline & \multicolumn{5}{c}{ Between Tests } \\
\cline { 2 - 6 } Encoding Condition & $1-2$ & $2-3$ & $3-4$ & $4-5$ & Total \\
\hline Gains & & & & & \\
$\quad$ 100-msec mask & 2.32 & 2.68 & 2.64 & 1.60 & 9.24 \\
$\quad$ 266-msec mask & 1.36 & 1.00 & 1.56 & 1.16 & 5.08 \\
$\quad$ Intact & 1.16 & 1.12 & 1.00 & 1.24 & 4.52 \\
Losses & & & & & \\
100-msec mask & 2.72 & 1.84 & 1.12 & 1.12 & 6.80 \\
266-msec mask & 2.64 & 1.56 & 1.48 & 1.04 & 6.72 \\
Intact & 1.84 & 1.12 & 1.24 & 0.84 & 5.04 \\
PF Scores & & & & & \\
100-msec mask & 0.75 & 1.42 & 2.07 & 2.26 & - \\
266-msec mask & 0.69 & 1.29 & 1.98 & 1.97 & - \\
$\quad$ Intact & 1.86 & 3.08 & 3.16 & 3.58 & - \\
\hline
\end{tabular}

Note-PF = bi-directional pair frequency scores (Sternberg \& Tulving, 1977).

Critically, however, the perceptual-interference effect emerged on the later recall tests.

The second set of analyses revealed a significant effect of test in the 100-msec mask condition $[F(4,96)=22.07$, $\left.M S_{\mathrm{e}}=1.74\right]$, indicating significant hypermnesia in this condition. Fisher's LSD test indicated that recall was higher on Tests 4 and 5 (which did not significantly differ from one another) than on the first three tests (which likewise did not differ). The effect of test was also significant in the 266-msec mask condition $\left[F(4,96)=4.47, M S_{\mathrm{e}}=\right.$ $2.94]$, which in contrast to the 100 -msec mask condition, reflects decreased recall over tests. For this condition, recall on Test 1 was significantly higher than on any of the other tests, and the other tests did not differ from one another. The effect of test was not significant in the intact condition $(F=1.75, p>.10)$.

Next the recall components (see Table 2) were analyzed. Item gains for test $i$ were computed as the number of words recalled on test $i$ but not on test $i-1$. Item losses for test $i$ were computed as the number of words recalled on test $i-1$, but not test $i$. The number of gains and losses were submitted to separate $3 \times 4$ ANOVAs, using encoding condition and recall test (2-5) as factors. For gains, the main effect of encoding condition was significant $\left[F(2,72)=25.87, M S_{\mathrm{e}}=1.606\right]$. The other effects were not significant $(F \mathrm{~s}<1.75, p \mathrm{~s}>.12)$. Post hoc comparisons indicated significantly more gains in the 100 -msec mask condition than in either the $266-\mathrm{msec}$ mask or the intact condition and that the latter two conditions did not significantly differ. The analysis of losses produced significant effects of encoding condition $\left[F(2,72)=3.69, M S_{\mathrm{e}}=\right.$ $1.674]$ and test $\left[F(3,216)=15.62, M S_{\mathrm{e}}=1.760\right]$. The latter result indicates greater losses on the earlier tests, especially between Tests 1 and 2, and is consistent with earlier studies (e.g., Mulligan, 2001; Payne \& Wenger, 1992). The interaction was not significant $(F<1)$. Post hoc comparisons indicated significantly fewer losses in the intact condition than in either the 100- or the 266-msec mask conditions and that the latter two conditions did not significantly differ. Thus, the 100-msec mask (the standard perceptual-interference condition) produced more gains and more losses than did the intact condition, whereas the 266-msec mask condition produced only more losses. ${ }^{2}$

In addition to item losses, relational encoding can also be assessed by the amount of organization in recall protocols (e.g., Hunt \& McDaniel, 1993; Mulligan, 2001), usually measured in terms of subjective organization in the case of unrelated study words and multiple tests (Sternberg \& Tulving, 1977). In the present study, the bidirectional pair frequency (PF) measure was used (Sternberg \& Tulving, 1977), a measure that is based on the number of word pairs recalled in adjacent positions on two successive tests, corrected for the expected number of chance pairings. PF scores (Table 2) were submitted to a 3 (encoding condition) $\times 4$ (recall test) ANOVA, which revealed a main effect of test $\left[F(3,216)=14.78, M S_{\mathrm{e}}=2.49\right]$, indicating that subjective organization increased over tests (Payne \& Wenger, 1992), a main effect of encoding condition $\left[F(2,72)=3.96, M S_{\mathrm{e}}=17.60\right]$, and no interaction $(F<1)$. Post hoc comparisons indicated greater subjective organization in the intact condition than in either the 100or the 266-msec mask condition and that the latter two conditions did not significantly differ.

Cumulative recall (the total number of studied words recalled across tests; Table 1) is reported for completeness. Cumulative recall was submitted to a 3 (encoding condition) $\times 5$ (recall test) ANOVA. All three effects were significant [encoding condition, $F(2,72)=3.45, M S_{\mathrm{e}}=82.86$; test, $F(4,288)=218.19, M S_{\mathrm{e}}=1.16$; and the interaction, $\left.F(8,288)=13.45, M S_{\mathrm{e}}=1.16\right]$. This indicates that cumulative recall was greatest in the 100 -msec mask condition, that recall increased over tests, and that the increase in cumulative recall was greatest in the $100-$ msec mask condition. The effect of encoding condition was not significant in Tests 1 and $2(F=0.82$ and 1.79 , respectively, $p s>.15)$ but was significant on the later tests [Test $3: F(2,72)=$ $3.90, M S_{\mathrm{e}}=17.23$; Test 4: $F(2,72)=6.60, M S_{\mathrm{e}}=17.23$; Test 5: $\left.F(2,72)=6.44, M S_{\mathrm{e}}=18.39\right]$. Post hoc tests indicated that recall in the 100 -msec mask condition was significantly higher than in the 266-msec mask condition on Test 3 and significantly higher than in either the 266-msec mask or the intact condition on Tests 4 and 5. The 266msec mask and intact conditions did not differ.

\section{DISCUSSION}

Great theoretical weight has been placed on the finding that the generation effect, as well as other effects mediated by enhanced item-specific processing, do not typically arise in between-subjects designs. The present study extends the results of Mulligan (2001) by showing that the perceptual-interference effect as well as the generation effect emerges in a between-subjects design as subjects are tested over multiple recall trials. Thus, this result holds for 
two distinct item-specific effects and motivates research to determine why item-specific processing leads to greater gains and greater losses over recall trials (some speculations are provided below). Hypotheses designed to account for the impact of experimental design on item-specific effects need to take this result into account. A complete reconsideration of these theories is beyond the scope of this article (see Mulligan, 2001). However, the present result is incompatible with two of the accounts outlined in the introduction - the selective rehearsal and task demand accounts (Begg et al., 1991; Slamecka \& Katsaiti, 1987; Westerman \& Greene, 1997). Both of these accounts propose that a between-subjects design induces the same type and amount of encoding across conditions. Contrary to these views, the emergence of a perceptual-interference effect on later recall tests indicates that there were latent encoding differences between the perceptual-interference and intact items that did not emerge on an initial test. The item-specific-relational account can accommodate the present results and is discussed below.

In addition to their theoretical importance, the present results are also helpful for the more specific goal of delineating the perceptual-interference effect. First, they demonstrate another similarity between the generation and perceptual-interference effects (Mulligan, 2000a; Nairne, 1988; Westerman \& Greene, 1997). Second, they indicate that a between-subjects manipulation is not a true limiting condition of the perceptual-interference effect.

The patterns of item gains and losses are informative in two ways. First, these results converge with Mulligan (2000b) in finding that perceptual interference (100-msec mask condition) increased both gains and losses relative to the intact condition, consistent with the view that perceptual interference enhances item-specific processing and disrupts relational encoding (Mulligan, 1999). Second, the results of the delayed mask (266-msec mask condition) cohere with the results of Mulligan (2000a). This condition produced no enhancement in item memory (Hirshman et al., 1994; Mulligan, 2000a). In addition, relative to the intact condition, the delayed mask produced more item losses but did not affect gains, implying that a delayed mask disrupts relational encoding but does not enhance item-specific information. Thus, the item-specific enhancements can be dissociated from the relational and order disruptions of the perceptual-interference manipulation (see Mulligan, 2000a, for theoretical implications).

The analysis of subjective organization converges with the loss analysis in implying reduced relational encoding for both masking conditions relative to the intact condition. This result is similar to that of Payne and Wenger (1992), who found that the condition producing greater subjective organization ( pictures relative to words in their study) also produced fewer losses. These results provide converging evidence on the validity of item losses as a measure of relational processing (e.g., Burns, 1993; Klein et al., 1989; McDaniel et al., 1998).

Although the present study was not designed to examine the phenomenon of hypermnesia per se, consider the result that hypermnesia was found in the 100-msec mask condition but not in the intact or 266-msec mask conditions. With respect to the intact condition, verbal materials typically do not produce hypermnestic recall unless the materials are presented multiple times or are encoded under instructions encouraging semantic elaboration or imagistic processing (e.g., Belmore, 1981; Payne, 1987). These conditions do not hold in the intact condition, so it is not surprising that this condition produces no increase in recall across tests. The 266-msec mask condition was expected to lead to more losses but not to more gains than the intact condition, which in turn predicts decreased recall across tests, in accord with the present findings (an unusual but not unprecedented finding; e.g., Klein, Loftus, \& Schell, 1994; Shaw \& Bekerian, 1991). A final point on the $266-\mathrm{msec}$ mask condition concerns its recall level compared with that of the intact condition. The present account that the 266-msec mask disrupts relational encoding but leaves unaffected item-specific encoding is supported by many aspects of the present results. However, this account also implies that the 266-msec condition should produce lower recall than should the intact condition. Although this was not found, it should be noted that the 266-msec mask condition produced nonsignificantly lower recall than did the intact condition on all five tests. Hirshman et al. (1994, Experiment 3) also found nonsignificantly lower recall in the 266-msec mask condition, as compared with the intact condition. Thus, six of six comparisons are in the predicted direction, although each was nonsignificant. It may be that the more direct measures of relational processing (subjective organization and item losses) are more sensitive to subtle disruptions of relational encoding than is overall correct recall.

The standard (100-msec mask) perceptual-interference condition produced hypermnesia. Although the itemspecific account predicts increased gains and increased losses in the 100-msec mask condition, it does not explicitly predict whether gains would outweigh losses to produce hypermnesia. However, an item-specific-relational account of hypermnesia developed by McDaniel et al. (1998, and applied to generation by Mulligan, 2001) is relevant. According to this view, relational information plays an important role in guiding retrieval strategies, and retrieval strategies become increasingly consistent over successive recall trials (Hunt \& McDaniel, 1993; McDaniel et al., 1998; Payne \& Wenger, 1992). An encoding condition that enhances item-specific processing (and disrupts relational processing) should produce more losses and minimal hypermnesia in the early tests. Under these conditions, this view predicts that hypermnesia will emerge on later tests, as the greater item recovery produced by itemspecific encoding continues and item losses are attenuated due to increasingly stable retrieval strategies. This view implies that the enhanced encoding of item-specific information in the 100-msec mask condition would be evinced in higher levels of recall on later tests (as consistent gains counteract progressively diminishing losses). Several of the present results are consistent with this interpretation: 
(1) Hypermnesia in the 100-msec condition did not arise until the later tests; (2) item losses were greater across earlier than across later tests (a typical result; e.g., McDaniel et al., 1998; Mulligan, 2001; Payne \& Wenger, 1992); and (3) subjective organization increased across tests (e.g., Payne \& Wenger, 1992).

\section{REFERENCES}

Atkinson, R. C., \& Shiffrin, R. M. (1968). Human memory: A proposed system and its control processes. In K. W. Spence \& J. T. Spence (Eds.), The psychology oflearning and motivation (Vol. 2, pp. 89-195). New York: Academic Press.

BegG, I., Vinski, E., Frankovich, L., \& Holgate, B. (1991). Generating makes words memorable, but so does effective reading. Memory \& Cognition, 19, 487-497.

Belmore, S. M. (1981). Imagery and semantic elaboration in hypermnesia for words. Journal of Experimental Psychology: Human Learning \& Memory, 7, 191-203.

BuRns, D. J. (1993). Item gains and losses during hypermnesic recall: Implications for the item-specific-relational information distinction. Journal of Experimental Psychology: Learning, Memory, \& Cognition, 19, 163-173.

Burns, D. J. (1996). The item-order distinction and the generation effect: The importance of order information in long-term memory. American Journal of Psychology, 109, 567-580.

De Losh, E. L., \& McDAniel, M.A. (1996). The role of order information in free recall: Application to the word-frequency effect. Journal of Experimental Psychology: Learning, Memory, \& Cognition, 22, 1136-1146.

Engelkamp, J., \& Dehn, D. A. (2000). Item and order information in subject-performed tasks and experimenter-performed tasks. Journal of Experimental Psychology: Learning, Memory, \& Cognition, 26, 671682.

Greene, R. L. (1992). Human memory: Paradigms and paradoxes. Hillsdale, NJ: Erlbaum.

Greene, R. L., Thapar, A., \& Westerman, D. L. (1998). Effects of generation on memory for order. Journal of Memory \& Language, 38, 255-264.

Hirshman, E., \& BJork, R. A. (1988). The generation effect: Support for a two-factor theory. Journal of Experimental Psychology: Learning, Memory, \& Cognition, 14, 484-494.

Hirshman, E., \& Mulligan, N. W. (1991). Perceptual interference improves explicit memory but does not enhance data-driven processing. Journal of Experimental Psychology: Learning, Memory, \& Cognition, 17, 507-513.

Hirshman, E., Trembath, D., \& Mulligan, N. W. (1994). Theoretical implications of the mnemonic benefits of perceptual interference. Journal of Experimental Psychology: Learning, Memory, \& Cognition, 20, 608-620.

Hunt, R. R., \& Elliott, J. M. (1980). The role of nonsemantic information in memory: Orthographic distinctiveness effects on retention. Journal of Experimental Psychology: General, 109, 49-74.

Hunt, R. R., \& McDaniel, M. A. (1993). The enigma of organization and distinctiveness. Journal of Memory \& Language, 32, 421-445.

Jurica, P. J., \& Shimamura, A. P. (1999). Monitoring item and source information: Evidence for a negative generation effect in source memory. Memory \& Cognition, 27, 648-656.

Klein, S. B., Loftus, J., Kinlstrom, J. F., \& Aseron, R. (1989). Effects of item specific and relational information on hypermnesic recall. Journal of Experimental Psychology: Learning, Memory, \& Cognition, 15, 1192-1197.

Klein, S. B., Loftus, J., \& Schell, T. (1994). Repeated testing: A technique for assessing the role of elaborative and organizational processing in the representation of social knowledge. Journal of Personality \& Social Psychology, 66, 830-839.

KuČERA, H. \& Francis, W. N. (1967). Computationalanalysis of presentday American English. Providence, RI: Brown University Press.

LI, S. C., \& LEWANDOWSKY, S. (1993). Intralist distractors and recall di- rection: Constraints on models of memory for serial order. Journal of Experimental Psychology: Learning, Memory, \& Cognition, 19, 895908.

McDaniel, M. A., DeLosh, E. L., \& Merritt, P. S. (2000). Order information and retrieval distinctiveness: Recall of common versus bizarre material. Journal of Experimental Psychology: Learning, Memory, \& Cognition, 26, 1045-1056.

McDaniel, M. A., \& Einstein, G. O. (1986). Bizarre imagery as an effective memory aid: The importance of distinctiveness. Journal of Experimental Psychology: Learning, Memory, \& Cognition, 12, 54-65.

McDaniel, M. A., Moore, B. A., \& Whiteman, H. L. (1998). Dynamic changes in hypermnesia across early and late tests: A relational/itemspecific account. Journal of Experimental Psychology: Learning, Memory, \& Cognition, 24, 173-185.

McDaniel, M. A., Wadill, P. J., \& Einstein, G. O. (1988). A contextual account of the generation effect: A three-factor theory. Journal of Memory \& Language, 27, 521-536.

Morris, C. D., Bransford, J. D., \& Franks, J. J. (1977). Levels of processing versus transfer appropriate processing. Journal of Verbal Learning \& Verbal Behavior, 16, 519-533.

Mulligan, N. W. (1996). The effects of perceptual interference at encoding on implicit memory, explicit memory, and memory for source. Journal of Experimental Psychology: Learning, Memory, \& Cognition, 22, 1067-1087.

Mulligan, N. W. (1999). The effects of perceptual interference at encoding on organization and order: Investigating the roles of item-specific and relational information. Journal of Experimental Psychology: Learning, Memory, \& Cognition, 25, 54-69.

Mulligan, N. W. (2000a). Perceptual interference and memory for order. Journal Memory \& Language, 43, 680-697.

Mulligan, N. W. (2000b). Perceptual interference at encoding enhances item-specific encoding and disrupts relational encoding: Evidence from multiple recall tests. Memory \& Cognition, 28, 539-546.

Mulligan, N. W. (2001). Generation and hypermnesia. Journal of Experimental Psychology: Learning, Memory, \& Cognition, 27, 436-450.

Mulligan, N. W., GuYer, P. S., \& Beland, A. (1999). The effects of levels-of-processing and organization on conceptual implicit memory in the category exemplar production test. Memory \& Cognition, 27, 633-647.

NAIRNE, J. S. (1988). The mnemonic value of perceptual identification. Journal of Experimental Psychology: Learning, Memory, \& Cognition, 14, 244-255.

Nairne, J. S., Reigler, G. L., \& Serra, M. (1991). Dissociative effects of generation on item and order retention. Journalof Experimental Psychology: Learning, Memory, \& Cognition, 17, 702-709.

PAYNE, D. G. (1987). Hypermnesia and reminiscence in recall: A historical and empirical review. Psychological Bulletin, 101, 5-27.

Payne, D. G., \& Wenger, M. J. (1992). Repeated recall of pictures, words, and riddles: Increasing subjective organization is not sufficient for producing hypermnesia. Bulletin of the Psychonomic Society, 30, 407-410.

RaAijmakers, J. G. W., \& Shiffrin, R. M. (1981). Search of associative memory. Psychological Review, 88, 93-134.

RoBERTS, W. A. (1972). Free recall of word lists varying in length and rate of presentation: A test of total-time hypotheses. Journal of Experimental Psychology, 92, 365-372.

Roediger, H. L., III, \& McDermott, K. B. (1993). Implicit memory in normal human subjects. In F. Boller \& J. Grafman (Eds.), Handbook of neurospychology (Vol. 8, pp. 63-131). Amsterdam: Elsevier.

Shaw, G. A., \& BeKERIAN, D. A. (1991). Hypermnesia for high-imagery words: The effects of interpolated tasks. Memory \& Cognition, 19, 87-94.

SlamecKa, N. J., \& KatSAiti, L. T. (1987). The generation effect as an artifact of selective displaced rehearsal. Journal of Memory \& Language, 26, 589-607.

Sperling, G. (1986). A signal-to-noise theory of the effects of luminance on picture memory: Comment on Loftus. Journal of Experimental Psychology: General, 115, 189-192.

Steffens, M. C., \& Erdfelder, E. (1998). Determinants of positive and negative generation effects in free recall. Quarterly Journal of Experimental Psychology, 51A, 705-733. 
Sternberg, R. J., \& Tulving, E. (1977). The measurement of subjective organization in free recall. Psychological Bulletin, 84, 539-556.

Westerman, D. L., \& Greene, R. L. (1997). The effects of visual masking on recognition: Similarities to the generation effect. Journal of Memory \& Language, $\mathbf{3 7}, 584-596$.

\section{NOTES}

1. This result holds primarily for unrelated study words. For related study words, generation effects are sometimes found in between-subjects designs (e.g., McDaniel, Wadill, \& Einstein, 1988).

2 . A concern might be raised that the 100 -msec mask condition produces more losses than does the intact condition because it leads to higher recall. That is, if more items are initially recalled, there are more to be forgotten on the next test. This is unlikely for several reasons outlined in Mulligan (2001). Generally, Payne's (1987) review indicated little relationship between initial recall level and losses (or gains). In addi- tion, this artifactual account would incorrectly predict equivalent losses in the 266-msec mask and intact conditions. Finally, if differential item loss is an artifact of initial recall level, restricting the analysis to losses occurring between Tests 1 and 2 and between Tests 2 and 3 (in which initial recall levels were equivalent across encoding conditions) should eliminate the outcome. It does not. The effect of encoding condition was significant over these tests $\left[F(2,72)=4.21, M S_{\mathrm{e}}=4.182\right]$, with pairwise comparisons revealing fewer losses in the intact condition than in either the 100- or the 266-msec mask conditions. Likewise, the effect of encoding condition was significant for gains $\left[F(2,72)=14.63, M S_{\mathrm{e}}=4.094\right]$, with pairwise comparisons revealing more gains in the 100 -msec mask condition than in either the 266-msec mask or the intact conditions.

(Manuscript received July 25, 2000; revision accepted for publication May 3, 2001.) 